\title{
The effects of alcohol on escape learning and on regular and punished extinction in a self-punitive situation with rats
}

\author{
A. J. SKURDAL, M. J. ECKARDT, and JUDSON S. BROWN \\ University of Oregon Medical School, Portland, Oregon 97201
}

\begin{abstract}
The effects of alcohol on aversively motivated locomotor behavior were examined using female rats in a short straight alleyway. A 2 by 2 by 2 factorial design included alcohol and no-alcohol conditions during escape training, and punishment or no punishment and alcohol or no alcohol during extinction of the escape response. Alcohol was found to interfere with acquisition of the escape response, to counteract the facilitatory effects of shock punishment, and to enhance performance during nonpunished extinction. The results are congruent with a traditional conditioned fear theory, amended by the notion that only partial fear responses are evoked under an inhibiting effect of alcohol. The results are also discussed in terms of state-dependency conceptions, with the addition of cue distinctiveness contributing to motivational and/or associational effects of alcohol.
\end{abstract}

In an exhaustive review of evidence bearing on the hypothesis that alcohol has tension-reducing functions, Cappell and Herman (1972) have concluded that the results of studies involving alcohol and aversively motivated behavior are largely equivocal and even contradictory. To cite but a few examples, the performance of rats in a variety of avoidance tasks is sometimes degraded by alcohol (Conger, 1951) but is often facilitated (Baum, 1969, 1970); motor activity increases on occasion (Broadhurst \& Wallgren, 1964) but on others it is reduced (Chittel \& Sheth, 1963; Wallgren \& Savolainen, 1962). Moreover, the theoretical interpretations of these diverse outcomes are equally contradictory, with increased fear or tension being invoked in some cases (Amit \& Baum, 1970) and decreased fear in others (Anisman, 1972) even when comparable treatments have been involved. Clearly, additional data are needed to illuminate the ways in which fear conditioning and such aversively motivated behaviors as escape and avoidance may be modulated by alcohol.

In the present experiment, several of these problems were investigated simultaneously by means of the so-called "self-punitive" paradigm (Brown, Martin, \& Morrow, 1964). This arrangement was chosen since it offered a wide variety of conditions and relations relevant to aversively motivated behavior. Specifically, the procedure involves an initial shock-escape training phase in a short straight runway followed by an "extinction" phase in which some subjects are never shocked whereas others are punished in the middle of

This research was supported by Training Grant MH 12640-02 and research grant No. 1 RO1 AAO 1229-01 from the National Institute on Alcohol Abuse and Alcoholism and Grant MH 23607-02 from the National Institutes of Health. the runway if, but only if, they enter that segment from shock-free starting and initial segments. Contrary to obvious expectations, punished subjects continue to run more swiftly and more persistently than do nonpunished animals (Brown, 1969). One of the currently popular interpretations of this "vicious circle" phenomenon, proposed originally by Mowrer (1947) and extended subsequently by Brown (1969) and Melvin (1971), entails the view that running during extinction is motivated by conditioned fear and that shock serves to recondition fear in the punished subjects, thereby facilitating their perseverative running. It seemed especially desirable to study the effect of alcohol on the self-punitive behavior of the rat because of a dearth of information on that topic-the only available study of drugs and self-punitive behavior involved the administration of chlorpromazine (Martin, Deemer, McArdle, Stokely, \& Steiner, 1971)-and because the results of studies with other species have supported different conclusions. For example, Chamove and Harlow (1970) have reported that self-aggression in monkeys is exaggerated by alcohol, whereas superficially similar behaviors in children (Dismang, 1970) and in chickens (Kovach, 1967) have been described as weakened by ethanol.

In our experiment, a 2 by 2 by 2 factorial design was employed that involved the presence or absence of alcohol during shock-escape training in a runway, and alcohol or no alcohol and punishment or no punishment during the extinction of the escape response. This design yielded information not only on the basic self-punitive phenomenon and the effects of alcohol thereon, but also on the effects of alcohol on the acquisition of a shock-escape response, on the conditioning and extinction of fear, and on the transfer of training from a state of inebriation to one of sobriety and vice versa. 


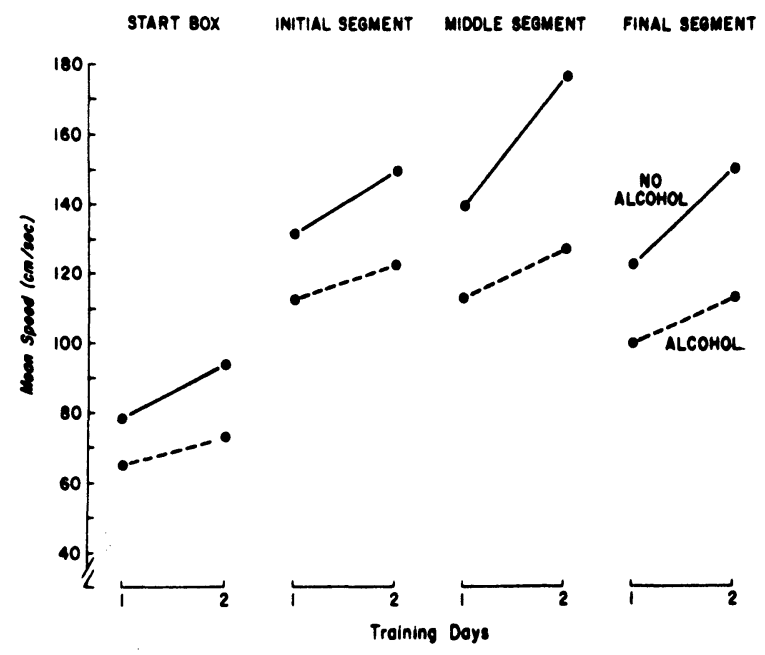

Figure 1. Running speeds during shock-escape training.

\section{METHOD}

\section{Subjects}

The subjects were 64 naive female albino rats (Sprague-Dawley derivatives from Carworth Farms, Inc., Portage, Michigan) 90-100 days of age at the beginning of the experiment. They were housed individually, with water and laboratory chow available ad lib throughout the experiment. The animals were run during the light phase of a normal $12-\mathrm{h}$ dark and 12-h light cycle.

\section{Apparatus}

The apparatus has been described in detail by Brown, Beier, and Lewis (1971). It consisted of a grid-floored starting section (42 $\mathrm{cm}$ long, $11.4 \mathrm{~cm}$ wide, $20.3 \mathrm{~cm}$ deep) surmounted by a trap-door-floored startbox $(22 \mathrm{~cm}$ long, $10 \mathrm{~cm}$ wide, $28 \mathrm{~cm}$ deep), a grid-floored runway $(183 \mathrm{~cm}$ long, $11.4 \mathrm{~cm}$ wide, $20.3 \mathrm{~cm}$ deep, inside), and a large goalbox $(145.7 \mathrm{~cm}$ long, $30.5 \mathrm{~cm}$ wide, $20.3 \mathrm{~cm}$ deep). The walls and floor of the goalbox were painted with black and white squares $(2.54 \mathrm{~cm}$ on a side) in a checkerboard pattern, whereas the walls of the runway and subflooring beneath the grid were painted medium gray. Hinged Plexiglas lids covered the entire apparatus. The grid was made of $2.4-\mathrm{mm}$ stainless steel rods spaced at $1.27-\mathrm{cm}$ intervals. Photocells and infrared light sources were located at the beginning of the runway and at intervals of $61 \mathrm{~cm}$ thereafter. They functioned in conjunction with auxiliary devices to provide measures of starting latency and of running times for each of the three $61-\mathrm{cm}$ segments. The $60-\mathrm{Hz}$ shock was controlled by a variable-voltage autotransformer and was fed to the grid through a series resistance of $10 \mathrm{~K}$ ohms. The voltmeter, which was connected across the grids at all times, had a full-scale calibration of $150 \mathrm{~V}$ ac and a sensitivity of $2,000 \mathrm{ohms} / \mathrm{V}$.

\section{Procedure}

The experimental design included the factors of alcohol or saline during escape training (T), alcohol or saline during extinction (E), and punishment or nonpunishment during extinction (P). The subjects were rand omly assigned to the eight cells of the 2 by 2 by 2 factorial design. They were run in squads of four, randomly chosen save that two members of each squad received alcohol injections and the other two received saline injections on any given day. Squad membership was maintained intact throughout the experiment.

The alcohol dosage was $1.2 \mathrm{~g}$ of alcohol $/ \mathrm{kg}$ of body weight. Absolute ethanol was mixed with distilled water to obtain a concentration of $20 \%$ (volume of alcohol per total solution volume). All injections were given intraperitoneally, a 3-min interval elapsing between any animal's injection and its first daily trial. Successive members of any one squad were run at intervals of approximately $30 \mathrm{sec}$

The animals were handled individually for $3 \mathrm{~min}$ on each of the 2 days subsequent to their arrival in the laboratory. These taming procedures were performed at the same time of day at which the experiment was scheduled to be conducted. On the 3rd day, half the rats were injected with alcohol and half with saline; they were then habituated to the goalbox for a total of $2 \mathrm{~min}$. Each rat was placed into the box four times, once in each corner, being free to explore for $30 \mathrm{sec}$. After each placement and removal, the rat was returned to the holding cage, there to remain while the other members of the squad were allowed to explore the goalbox. Thus, the interval between successive 30 -sec goalbox placements was approximately $2 \mathrm{~min}$.

Shock-escape shaping trials, consisting of five trials involving progressively longer segments of the runway, were administered on Day 4. For the first trial, the startbox was placed next to the goalbox so that the animals could reach safety after traversing only $10 \mathrm{~cm}$ of electrified grid. On the second and third trials, the rats had to cross an additional $61 \mathrm{~cm}$ to reach the goalbox. On the fourth trial, the runway length was increased to $122 \mathrm{~cm}$. Trial 5 involved the start section plus the entire $183-\mathrm{cm}$ alley. Subjects were allowed to remain in the goalbox for $30 \mathrm{sec}$ following each trial and were then returned to the holding cage. All animals were injected with the same solution as on the previous exposure day.

Days 5 and 6 involved additional shock-escape training (full-length runway), with five trials given per day. Squad members were run on a rotational basis, so that the intertrial interval was about $3 \mathrm{~min}$. All animals were injected as they had been on previous days.

On Day 7, extinction conditions were initiated. Half of the animals trained with alcohol injections were switched to saline and half the animals trained with saline were switched to alcohol. In addition, half the subjects in each of the four groups (alcohol-alcohol, A-A; alcohol-no alcohol, A-NA; no alcoholno-alcohol, NA-NA; no alcohol-alcohol, NA-A) were given punished extinction trials and half were given nonpunished extinction trials. Nonpunished animals received no shock in any portion of the runway, whereas punished animals received shock (identical to training intensity) in the middle $61-\mathrm{cm}$ segment of the runway. Rats failing to enter the goalbox within $60 \mathrm{sec}$ on any trial were removed from the runway and not run again. Recorded times for segments completed on that trial were used as data unless they exceeded $15 \mathrm{sec} / \mathrm{segment}$, in which case a 15-sec score was assigned. Fifteen-second times were then assigned for each segment not completed, as well as for the start and runway segments for all subsequent days of experimentation.

\section{RESULTS}

Daily five-trial median running times were determined for each animal for the startbox segment and for each of the three alley segments. These medians, when converted into speeds $(\mathrm{cm} / \mathrm{sec})$, served as the basic data in the analyses of variance of performances during acquisition and extinction.

\section{Shock-Escape Acquisition Data}

Mean speeds in each of the four segments on the last 2 days of shock-escape training are shown in Figure 1. The main effect of days was significant in every segment (all ps $<.01$ ) as was the main effect of the drug (all ps $<.01)$. In the middle and final alley segments only, 

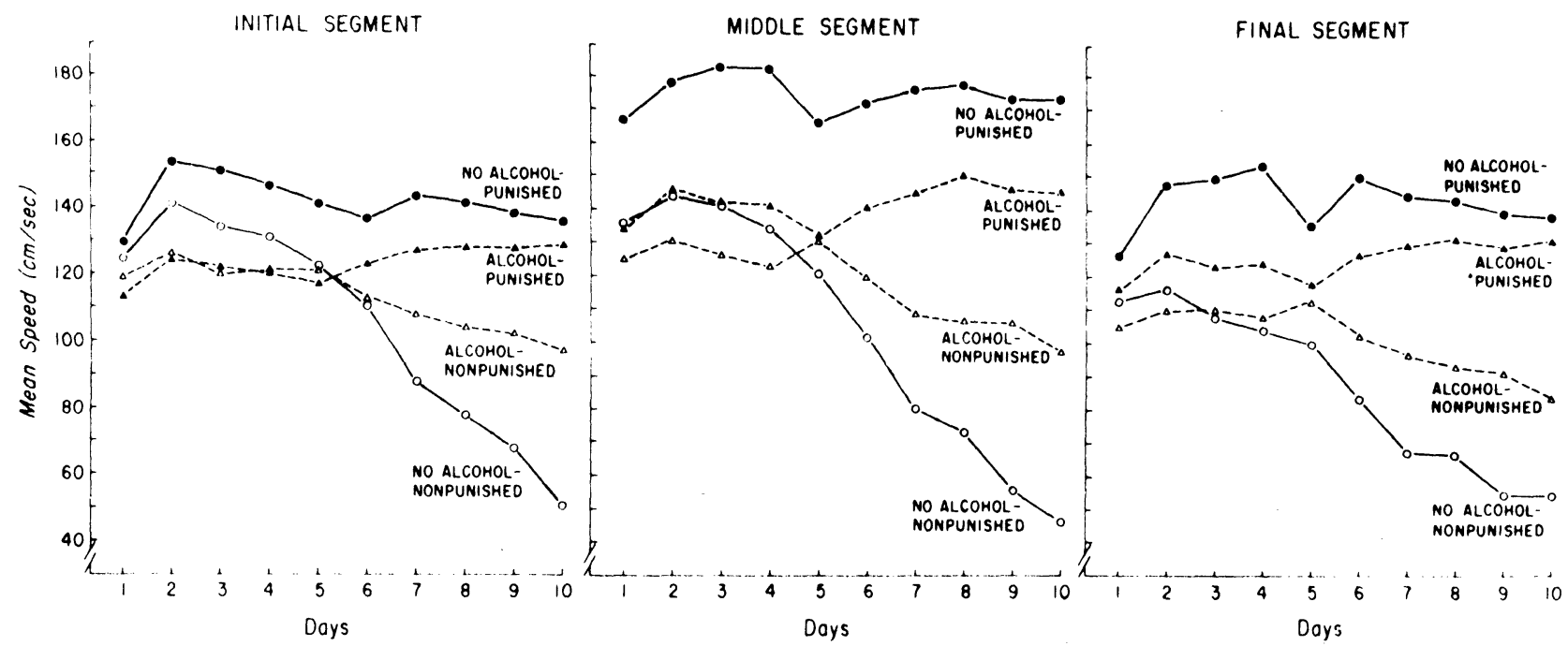

Figure 2. Running speeds during extinction: DEP interaction.

animals trained with saline increased their speeds significantly more from Day 1 to Day 2 than did alcohol-trained animals (middle segment: $F=18.4$, $\mathrm{df}=1 / 62, \mathrm{p}<.01 ;$ final segment: $F=15.3, \mathrm{df}=1 / 62$, $p<.01)$. Clearly, the acquisition of shock-escape behavior was depressed by alcohol.

\section{Extinction Data}

Starting Segment Speeds. An overall analysis of speeds in the starting section yielded only two significant outcomes: A main effect of days $(F=3.10, d f=9 / 504$, $\mathrm{p}<.001)$ and a Days by Punishment interaction $(\mathrm{F}=3.18, \mathrm{df}=9 / 504, \mathrm{p}<.001)$. The starting speeds of the nonpunished animals decreased over days, whereas those for the punished rats were slightly faster on Day 10 than on Day 1.

Alley-Segment Speeds. Separate overall analyses were made of the speed data for each of the three alley segments. Of the four main effects, namely: days (D), punishment $(\mathrm{P})$, alcohol during training $(\mathrm{T})$, and alcohol during extinction (E), the first two were significant in all three analyses (all ps $<.001)$. The last two were significant in none. The running speeds of the nonpunished rats declined over days, whereas the punished subjects showed no signs of extinguishing. Indeed, in the third segment, the punished animals ran significantly faster on Day 10 than on Day $1(F=8.64$, $\mathrm{df}=1 / 504, \mathrm{p}<.01)$. This is consistent with the results of previous studies of self-punitive behavior.

Constraints upon the interpretation of the significant main effects were provided by the presence of significant double (DE, DP, and EP) and triplc (DEP) interactions in all three analyses (all ps $<.05$ ). The principal characteristics of these interactions are delineated in Figure 2 where the mean speeds, by segments, of groups involved in the DEP interactions have been plotted. As these curves show, the Days by Punishment (DP) interactions were due essentially to the fact that the punished groups (combined across drug conditions) were running slightly faster on Day 10 than on Day 1 whereas the nonpunished subjects were running significantly more slowly (in every segment) on Day 10 than on Day 1 (all ps <.05). The Days by Alcohol During Extinction interaction (DE) reflects a tendency for the nonalcohol subjects (collapsed across punishment conditions) to run faster than drugged animals at first but to slow down more over the course of extinction. The EP interactions arose from the faster running of the nonalcohol subjects under punishment in addition to their slower running in the absence of punishment. The triple interactions, of course, may be viewed in the usual way as simple interactions of any one of the three factors with the double interactions of the other two. Visual comparisons among the three panels indicate that shock in the middle segment increased the speeds of the punished groups, the effect being especially marked in the case of the nonalcohol animals. In the final segment, the speeds returned to levels exhibited in the first section.

As the foregoing implies, the role played by alcohol during extinction was confined to its interactions with other variables. The main effect of the drug during extinction (E) fell short of significance in the analyses data from all three segments (all ps $>.27$ ).

The relative resistance to extinction of the nonpunished groups trained with and without alcohol provides an estimate of the effect of alcohol on the conditioning of fear during shock-escape training. This involves the assumption that running in the absence of shock during extinction was motivated primarily by fear 
Table 1

Initial Segment, First Extinction Trial Mean Running Speeds

\begin{tabular}{lcc} 
& \multicolumn{2}{c}{ Extinction $(\mathrm{cm} / \mathrm{sec})$} \\
\cline { 2 - 3 } Training & Alcohol & No Alcohol \\
\hline Alcohol & 102.2 & 93.9 \\
No Alcohol & 92.2 & 113.9 \\
\hline
\end{tabular}

conditioned during the shock-escape phase. In an analysis of data from the initial segment for only the four nonpunished groups, neither the main effect of drug during training (T) nor of drug during extinction (E) was significant (both Fs $<1.0$ ). Changes occurring over days of extinction were significant, as were the $D E$ and DT interactions (all three ps <.05). Graphic plots of the DT interactions (not included here) for the nonpunished subjects showed that those trained under alcohol ran more slowly at the beginning of extinction but more rapidly at the end than did the nonalcohol animals. The average drop in speed exhibited by the latter rats was greater than the drop in speed shown by the alcohol-trained animals. For statistical analyses, Day 1-Day 10 difference scores were obtained for each animal and the means of these scores for the alcohol-trained and nonalcohol-trained groups were compared by $\mathrm{t}$ tests. The results approached significance in the initial segment (two-tailed $t=1.90, \mathrm{df}=30$, $\mathrm{p}<.10)$ and were significant in the middle $(\mathrm{t}=2.71$, $\mathrm{df}=30, \mathrm{p}<.02)$ and final segments $(\mathrm{t}=2.98, \mathrm{df}=30$, $\mathrm{p}<.01)$.

If distinctive internal cues are provided by alcohol, responses would presumably become associated with them, and animals trained with the drug should suffer a performance loss when tested without it. Similarly, animals trained without the drug and extinguished with it might be affected by the changed stimulus conditions. Presumably, the most sensitive indications of these "state dependent" or "stimulus generalization decrement" effects would be the early-trial speeds of all animals in shock-free segments or early-trial speeds of nonpunished rats in all segments. One such measure, the first-trial, start-section speeds for all subjects, failed to support a state dependent interpretation since the critical interaction of alcohol during training $(\mathrm{T})$ with alcohol during extinction (E) was not significant $(\mathrm{F}=.5)$. However, the mean initial-segment speeds of all subjects on the first trial of extinction only (no animal was shocked until it reached the second segment) were consistent with the dependency hypothesis. These means are presented in Table 1. The speeds of the shifted groups were slower than those of the nonshifted animals and, while the main effects of $T$ and of $E$ were not significant, the $T E$ interaction was $(F=6.82, d f=1 / 60$, $\mathrm{p}<.05)$.

A similar measure of "state dependency" was provided by the speeds in all segments, on the first five extinction trials on Day 1, for nonpunished subjects only. Analyzed by segment, these data also yielded significant TE interactions in the first and middle segments $(F=8.4, \quad d f=1 / 28, \quad p<.01 ; \quad F=5.3$, $\mathrm{df}=1 / 28, \mathrm{p}<.05)$ with switched subjects again tending to perform more poorly than nonswitched ones. The effect of alcohol during training $(\mathrm{T})$ was significant in all three segments (all ps $<.05$ ), with alcohol-trained rats running more slowly, but the effect of alcohol during extinction (E) was not significant in any segment. When identical analyses were carried out with the Day 10 scores (five trials) for the same subjects, none of the TE interactions was significant. The effect of alcohol during extinction was significant in every segment (all ps $<.05$ ) but the $T$ effect was not. When speed scores for all days for all subjects were included, no evidence was obtained to support a state-dependent view, none of the four TE interactions being significant. The DTE interaction was significant $(F=1.90, d f=9 / 504$, $\mathrm{p}<.05)$ in the middle-segment data but not elsewhere, and none of the other interactions involving both $E$ and $T$ was reliable. A plot of the DTE interaction showed that the direction of the difference was consistent with a state dependent prediction on Day 1 but was reversed on Day 10.

\section{DISCUSSION}

Analyses of running speeds recorded during the shock-escape phase of this study showed that the acquisition of locomotor-escape behavior was significantly retarded by alcohol. This result confirms the findings of Pawlowski, Dennenberg, and Zarrow (1951) and of Barry and Miller (1965). Differences in conditioned fear or emotionality seem inadequate to explain this outcome, since secondary motivational inequalities, if present, would presumably be overridden by the more potent dynamogenic effects of the shock. The inferior escape performance of the inebriated animals is consistent, however, with a motor-impairment conception. The movements of such subjects were poorly coordinated, and they often weaved "drunkenly" from side to side while progressing toward the goalbox. In addition, ethanol may have had an analgesic effect (Freed, 1971) resulting in a reduction in the effective intensity of the shock and hence in its activating and reinforcing powers. Were this the case, the conditioned fear reactions of the alcohol-trained animals should perhaps have been weaker than those of rats trained with saline, and, in the absence of further shocks, the former subjects should have resisted extinction less well than the latter. This expectation was not supported by the data, however, since the nonpunished alcohol-trained subjects, though slower at the start, were faster at the end of extinction than the saline-trained nonpunished subjects.

The finding that punishment facilitated the performance of subjects extinguished without alcohol coincides with the results of previous studies of self-punitive behavior (cf. Melvin, 1971). However, the finding of significant EP and DEP interactions in the data from all three alley segments indicates that the 
self-punitive effect was altered by alcohol. As is evident from the curves in Figure 2, the effect, though present under alcohol, was attenuated. The reduction of the difference between the inebriated punished and nonpunished subjects was due not only to the faster speeds of nonpunished animals (discussed below), but was also due, in part, to the slow speeds of the punished rats. As the middle panel of Figure 2 shows, shock dramatically enhanced the running of sober subjects-the usual effect in this situation-but exerted a smaller accelerative effect on the performance of the inebriated subjects. Whether ethanol lowered their performance ceiling by producing muscular incoordination or functioned in some other way remains to be determined.

In an experiment on the effects of chlorpromazine on self-punitive behavior, Martin et al (1971) observed that chlorpromazine had a marked (dose-related) tendency to reduce vicious-circle behavior. However, chlorpromazine decreased the performance of both punished and nonpunished animals. Since, in the present study, alcohol had differential effects on punished and nonpunished rats, its effect is ostensibly not the same as that of chlorpromazine.

Facilitation of the performance of the nonpunished alcohol subjects during the final days of extinction was apparent in all runway segments. Results similar to those of the present study have been reported by Baum (1971), who noted that ethanol increased resistance to extinction in several experiments involving an avoidance paradigm, a result he termed "paradoxical." The likelihood that increased resistance to extinction in the present experiment was due to an alcohol-aroused fear in pharmacologically naive animals (Amit \& Baum, 1970) seems remote since, at the time the effect appeared, our animals had experienced 10 intoxications and had traversed the alley 40 times under the influence of alcohol. An additional finding inconsistent with alcohol-aroused fear was that drugged animals punished during extinction ran more slowly than punished sober animals.

Since the saline-treated animals were running more slowly during the final days of extinction than the alcohol-treated (both groups nonpunished), a motor-impairment conception is also not congruent with the results, and other possibilities must be considered.

Barry, Wagner, and Miller (1962) reported that running speeds were elevated by alcohol during extinction of a food-rewarded locomotor response. Assuming that inhibition causes extinction of an appetitively motivated response, they concluded that alcohol interfered with the performance of that inhibition. Results favoring such an interpretation of the effects of alcohol have been proffered by Litner and Weisman (1970)., who found that ethanol blocked the effectiveness of a CS- in altering the rate of an avoidance response. If inhibition is responsible for extinction of the escape response, then interference with the process via alcohol injection would account for the perseverating performance of inebriated animals in the present study. Whether such an account will serve to explain the behavior of the punished animals is unclear, however. Presently available theoretical analyses of self-punitive behavior do not include discussion of the effects of inhibition on the performance of self-punitive animals. It is possible that whatever inhibition is generated during selfpunitive running is overcome by the more potent effects of the shock encountered in the middle alley segment.

A second alternative is that alcohol provided more intense and hence more motivating or more salient internal stimulus cues than did the saline. If the marked central effects of alcohol provided more cues and/or more distinctive cues to be paired with running for the inebriated animals during escape training, the presence of those cues during extinction would have been more effective in maintaining the running response for nonswitched alcohol animals than for animals running soberly during extinction. Consistent with this supposition is the fact that the nonpunished alcohol-trained rats that were switched to saline slowed down more during extinction than the animals that were switched from saline to alcohol. Indeed, the extinction performance of the former group was, in general, the poorest of all.

Some of the data can be explained by the state dependency concept (cf. Overton, 1972), which, like a stimulus generalization decrement hypothesis, leads to the expectation that animals trained and extinguished under identical stimulus conditions (internal and/or external) should resist extinction better than subjects for which the training and extinction conditions differed. As has been noted in the results section, the interaction of the drug during training (T) with the drug during extinction (E), especially when only early-trial data from nonpunished animals were evaluated, was deemed to provide the most appropriate evidence relative to the state dependency notion. The several significant TE interactions obtained with such data in this study support a state dependency theory. The fact that TE interactions were not significant when escape performance was contrasted on the last day of extinction also makes sense, since it seems plausible that the effect should be maximal immediately after the switch from acquisition to extinction and should weaken over days. The lack of significant TE interactions when all extinction data were included fits with the idea that the effect should disappear with days and with the notion that punishment should exert a confounding influence.

When two groups differ during extinction even though the stimulus conditions for : : ither group have been changed from acquisition to extinction, some concept 
other than state dependency must be invoked. In the present study, two such groups were the nonpunished animals trained and tested with alcohol and those trained and tested without alcohol. The fact that the former subjects maintained a significantly higher rate of locomotion than the latter throughout the terminal days of extinction cannot be deduced from either the state dependency or stimulus generalization notions, as these are usually formulated. Either conception would serve, however, were it modified to include the factor of stimulus intensity or distinctiveness. As has been noted above, the saline-produced cues may have been too weak to mediate the transfer of behavior learned during acquisition even though stimulus conditions were not altered across the transition. But the alcohol cues, if more intense, might have successfully mediated the transfer of running from the shock to the nonshock conditions.

The conditioned-fear theory of self-punitive behavior (Brown, 1969; Mowrer, 1960) generates the prediction that any factor working to diminish the effectiveness of shock in reconditioning the fear of punished animals or to weaken the fear aroused by the situation would attenuate vicious-circle behavior. The degraded performance of the shocked, ethanol-tested subjects is consistent with this view, but, without modification, the conditioned-fear theory cannot handle the behavior of the nonpunished rats since those that were inebriated were running more swiftly at the last than the sober ones. The theory will serve, however, if it is amended by the addition of Cappell and Herman's (1972) notion that only partial fear responses are evoked under an inhibiting effect of alcohol and that both slow running early in extinction (due to lowered level of motivation) and greater resistance to extinction of both fear and running will result. In effect, alcohol serves to maintain fear over repeated trials without punishment, not by eliminating it, but by preventing its full-strength evocation. Such a process is reminiscent, to a degree, of the anxiety-conservation theory of Solomon and Wynne (1954).

\section{REFERENCES}

Amit, Z., \& Baum, M. Comment on the increased resistanceto-extinction of an avoidance response induced by certain drugs. Psychological Reports, 1970, 27, 310.

Anisman, H. Fear reduction and active avoidance learning following administration of alcohol during prior CS-shock exposure. Quarterly Journal of Studies on Alcohol, 1972, 33, 783-793.

Barry, H. III, \& Miller, N. E. Comparison of drug effects on approach, avoidance, and escape motivation. Journal of Comparative and Physiological Psychology, 1965, 59, 18-24.

Barry, H. III, Wagner, A. R., \& Miller, N. E. Effects of alcohol and amobarbital on performance inhibited by experimental extinction. Journal of Comparative and Physiological Psychology, 1962, 55, 464-468.

Barry, H. III, \& Wallgren, H. A further note on preparing alcohol solutions. Quarterly Journal of Studies on Alcohol, 1968, 29 176-178.

Baum, M. Paradoxical effect of alcohol on the resistance to extinction of an avoidance response in rats. Journal of
Comparative and Physiological Psychology, 1969, 69, 238-240.

Baum, M. Effect of alcohol on the acquisition and resistance-to-extinction of avoidance responses in rats. Psychological Reports, 1970, 26, 759-765.

Baum, M. Effect of alcohol on the resistance-to-extinction of an avoidance response: Replication in mice. Physiology and Behavior, 1971, 6, 307-309.

Broadhurst, P. L., \& Wallgren, H. Ethanol and the acquisition of a conditioned avoidance response in selected strains of rats. Quarterly Journal of Studies on Alcohol, 1964, 25, 476-489.

Brown, J. S. Factors affecting self-punitive locomotor behavior. In Campbell, B. and Church, R. M. (Eds.), Punishment and aversive behavior. New York: Appleton-Century-Crofts, 1969.

Brown, J. S., Beier, E. M., \& Lewis, R. W. Punishment-zone distinctiveness and self-punitive locomotor behavior in the rat. Journal of Comparative and Physiological Psychology, 1971, 77, 513-520.

Brown, J. S., Martin, R. C., \& Morrow, M. W. Self-punitive behavior in the rat: Facilitative effects of punishment on resistance to extinction. Journal of Comparative and Physiological Psychology, 1964, 57, 127-133.

Cappell, H., \& Herman, C. P. Alcohol and tension reduction: A review. Quarterly Journal of Studies of Alcohol, 1972, 33, 33-64.

Chamove, A. S., \& Harolow, H. F. Exaggeration of self-aggression following alcohol ingestion in rhesus monkeys. Journal of Abnormal Psychology, 1970, 75, 207-209.

Chittal, S. M., \& Sheth, U。 K. Effect of drugs on conditioned avoidance response in rats. Archives internationales de Pharmacodynamie et de Therapie, 1963, 144, 471-480.

Conger, J. J. The effects of alcohol on conflict behavior in the albino rat. Quarterly Journal of Studies on Alcohol, 1951, 12 1-29.

1. $\mathrm{H}$. Personal communication. Cited by Chamove, A S., \& Harlow, H. F. Exaggeration of self-aggression following alcohol ingestion in rhesus monkeys. Journal of Abnormal Psychology, 1970, 75, 207-209.

Freed, E. X. Alcohol and conflict: Role of drug-dependent learning in the rat. Quarterly Journal of Studies on Alcohol, $1971,32,13-28$.

Freund, G. Impairment of shock-avoidance learning after long-term alcohol ingestion in mice. Science, 1970, 168, 1599-1601.

Kovach, J. K. Maternal behavior in the domestic cock under the influence of alcohol. Science, 1967, 156, 835-837.

Litner, J. S., \& Weisman, R. G. The effects of alcohol on the conditioned excitation and inhibition of fear. Paper presented at the meeting of the Canadian Psychological Association, Winnipeg, Manitoba, May, 1970. (Cited by Cappell, H., \& Herman, C. P.) Alcohol and tension reduction: A review. Quarterly Journal of Studies on Alcohol, 1972, 33, 33-64.

Martin, R. C., Deemer, B. L., McArdle, N., Stokely, S., \& Steiner, S. The effects of chlorpromazine on self-punitive behavior. Psychonomic Science, 1971, 23, 339-340.

Masserman, J. H., \& Yum, K. S. An analysis of the influence of alcohol on experimental neurosis in cats. Psychosomatic Medicine, 1946, 8, 36-52.

Melvin, K. B. Vicious circle behavior. In H. D. Kimmel (Ed..), Experimental psychopathology: Recent research and theory. New York: Academic Press, 1971.

Mowrer, O. H. On the dual nature of learning: A re-interpretation of "conditioning" and "problem-solving." Harvard Educational Review, 1947, 17, 102-148.

Mowrer, O. H. Learning theory and behavior. New York: Wiley, 1960.

Overton, D. A. State-dependent learning produced by alcohol and its relevance to alcoholism. In B. Kessin and $H$. Begleiter (Eds.), The biology of alcoholism: Vol. 2. New York-London: Plenum Press, 1972.

Pawlowski, A. A., Denenberg, V. H., \& Zarrow, M. X. Prolonged alcohol consumption in the rat. II. Acquisition and extinction of an escape response. Quarterly Journal of Studies on Alcohol, 1961, 22, 232-240.

Solomon, R. L., \& Wynne, L. C. Traumatic avoidance learning: The principles of anxiety conservation and partial irreversibility. Psychological Review, 1954, 61, 353-385.

Wallgren, H., \& Savolainen, S. The effect of ethyl alcohol on a conditioned avoidance response in rats. Acta pharmacologica et to xicologica, $\mathrm{Kbh}, 1962,19,59-67$.

(Received for publication August 22, 1974 accepted September 10, 1974.) 